GEOPHYSICAL RESEARCH LETTERS, VOL. 12, No. 8, PAGES 495-497, AUGUST 1985

\title{
IN-SITU MEASUREMENTS OF NITRIC OXIDE IN THE HIGH LATITUDE UPPER STRATOSPHERE
}

Jack J. Horvath

Space Physics Research Laboratory, The University of Michigan

John E. Frederick

Atmospheric Chemistry and Dynamics Branch, Code 616, NASA/Goddard Space Flight Center

Abstract. A rocket-launched parachutedeployed chemiluminescence sensor measured the vertical profile of nitric oxide from Poker Flat, Alaska, latitude 65.13 degress North, in August 1984 and in January and February 1985. All data refer to daylight periods shortly after local noon and cover altitudes from a lower limit of $27-30 \mathrm{~km}$ up to $48-53 \mathrm{~km}$. Between 35 and $45 \mathrm{~km}$ the results indicate a large seasonal variation, with wintertime mixing ratios being roughly a factor of two above summer values. The winter profiles contained sharp positive vertical gradients that persisted through the highest altitudes observed, and near $50 \mathrm{~km}$ the mixing ratio from the Feburary flight exceeded that seen in summer by a factor of four. Above the stratopause the mixing ratio observed in February increased dramatically and between 52 and $53 \mathrm{~km}$ reached $148.9 \mathrm{ppbv}$, an order of magnitude greater than typical mid-latitude values measured with this instrument. Such behavior is consistent with the absence of photodissociation in winter and a downward flux of odd nitrogen arising from a source located significantly higher than the stratopause, almost surely in the lower thermosphere. These results clearly support the existence of a vertical coupling between diverse regions of the atmosphere in the high latitude winter.

\section{Introduction}

Theoretical considerations suggest a large seasonal variability in middle atmospheric odd nitrogen ( $\mathrm{NO}_{\mathrm{x}}$ ) at high latitudes. On a globally averaged basis photodissociation of mesospheric nitric oxide followed by recombination to $\mathrm{N}_{2}$ forms an effective barrier between the large abundances characteristic of the lower thermosphere (e.g. Rusch, 1973; Cravens and Stewart, 1978) and the much smaller mixing ratios at stratospheric levels (Horvath et al. 1983). However, the chemical lifetime of mesospheric odd nitrogen varies greatly with season and latitude. For example, at 65 degrees latitude in summer and an altitude of $50 \mathrm{~km} \mathrm{a}$ characteristic time for chemical removal of $\mathrm{NO}_{\mathrm{x}}$ lies in the vicinity of 10 to 30 days, while a value of $100-300$ days is more appropriate to the same location in winter (Frederick and orsini, 1982). Furthermore, in winter at high latitudes mean vertical motion is downward, which when coupled with the weakness or, in the polar night, the absence of dissociation supports the possibility of an intrusion of large $\mathrm{NO}_{\mathbf{x}}$ mixing

Copyright 1985 by the American Geophysical Union.

Paper number $5 \mathrm{~L} 6575$.

0094-8276/85/005L-6575\$03.00 ratios, characteristic of much higher altitudes, into the upper stratosphere (Strobel et al, 1970). The opposite situation prevails in summer. Consistent with this reasoning, satellite-based remote sensors have observed polar night $\mathrm{NO}_{2}$ mixing ratios as large as 175 pobv at $70 \mathrm{~km}$ (Russell et al., 1984), and enhanced high latitude wintertime NO abundances integrated over stratospheric and mesospheric altitudes (Frederick and Serafino, 1985). Atmospheric models that treat the coupling of transport and chemistry have also predicted this behavior (Solomon et al., 1982; Solomon and Garcia, 1984).

In this letter we report results obtained from a set of three nitric oxide measurements conducted at high latitudes in summer and winter. These constitute the first in-situ No data that define the high latitude annual behavior. The observed seasonal differences are qualitatively consistent with the reasoning presented above.

\section{Instrumentation and Flights}

The instrument flown here was the rocketlaunched parachute-deployed chemiluminescence sensor described in detail by Horvath et al. (1983). Data are recorded over the altitude range from a lower Iimit of $27-30 \mathrm{~km}$ up to $48-$ 53. Briefly, atmospheric air containing ambient nitric oxide flows through the instrument as it descends on a parachute. This air is mixed with an excess of ozone drawn from an onboard storage volume, and the reaction of NO with $\mathrm{O}_{3}$ produces excited $\mathrm{NO}_{2}$ which fluoresces. Measurement of this emission in the instrument reaction chamber allows a derivation of the atmospheric nitric oxide mixing ratio. Table 1 summarizes the measurements reported in this paper. Poker Flat, Alaska located at 65.13 degress North and 147.48 degrees West was the launch site for all three flights. Resource constraints limited the maximum number of launches to three. We therefore chose to conduct only one measurement in surmer when the atmosphere is relatively quiescent and zonally symetric. In winter when the atmosphere is dymamically active and longitudinal variations are pronounced, we scheduled two launches spaced several days apart. The results therefore provide an indication of short term variability in the high latitude winter stratosphere.

A special constraint applied to the winter flights. In the absence of sunlight nitric oxide converts to other forms of odd nitrogen, being $\mathrm{NO}_{2}, \mathrm{NO}_{3}$, and $\mathrm{N}_{2} \mathrm{O}_{5}$. Al though we wished to obtain data as close to the polar night as possible, it was necessary to conduct measurements in daylight both for logistical 
TABLE 1. Supporting Information for the Nitric Oxide Measurements ${ }^{1}$

\begin{tabular}{llcc} 
Date & $\begin{array}{c}\text { Local Time } \\
\text { (hours) }\end{array}$ & $\begin{array}{c}\text { Solar } \\
\text { Zenith } \\
\text { Angle (o) }\end{array}$ & $\begin{array}{c}\text { Altitude } \\
\text { Range Covered } \\
(\mathrm{km})\end{array}$ \\
\hline August 16, 1984 & $12: 40$ & 52.5 & $29.91-49.95$ \\
January 28, 1985 & $13: 10$ & 83.2 & $27.15-48.20$ \\
February 7, 1985 & $13: 01$ & 82.9 & $27.49-52.25$
\end{tabular}

$\overline{1}_{\mathrm{All}}$ measurements were conducted from poker Flat, Alaska, latitude 65.13 degrees North, longitude 147.48 degrees West.

reasons and to assure that a significant fraction of $\mathrm{NO}_{\mathrm{x}}$ existed in the form of $\mathrm{NO}$ at the altitudes of interest. In addition, if a significant flow of odd nitrogen into the polar upper stratosphere from higher altitudes indeed occurs, this should be most evident after several months of a wintertime dynamical regime. However, the return of extended daylight periods would reduce the odd nitrogen chemical lifetime in the mesosphere, effectively terminating the coupling between different altitude regions. The period from late January to early February satisfied the criteria for several hours of daylight at Poker Flat and a time of year when the consequences of a downward flux of odd nitrogen should appear in the upper stratospheric No profile. All flights were conducted within one hour and ten minutes of local noon.

\section{Result}

Figure 1 presents the nitric oxide mixing ratio profile observed over Poker Flat on August 16, 1984. The error bars, given approximately every $5 \mathrm{~km}$, include uncertainties associated with counting statistics and instrument gas flow

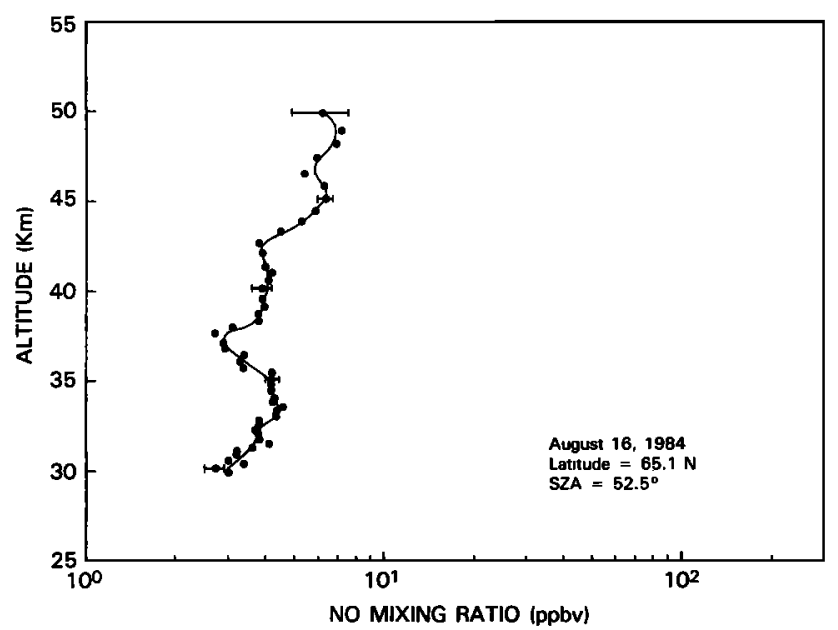

Fig. 1. Nitric oxide mixing ratio profile observed over Poker Flat, Alaska on August 16, 1984. Error bars given approximately every $5 \mathrm{~km}$ indicate uncertainties associated with count rates and measurement of gas flow parameters in the instruments. parameters. These are +7.1, 7.4, and 15.18 near 30,40 , and $49 \mathrm{~km}$ respectively. The absolute nitric oxide mixing ratios observed near $30 \mathrm{~km}$ are very similar to those reported previously at mid-latitudes (Horvath et al. 1983). However, near $40 \mathrm{~km}$ the high latitude summer value, 3.94.0 ppov, is only half of the 8.0-9.0 ppbv that was typical in measurements conducted from Wallops Island, Virginia. Near $50 \mathrm{~km}$ the Poker Flat mixing ratio of 6.2 ppbv compares to a range of 12-16 ppbv observed at mid-latitudes during July and August of previous years (Horvath et al. 1983).

The Poker Flat NO profile measured on January 28, 1985 appears in Figure 2. Between 30 and 34 km the mixing ratios are very similar to those seen in August. However a positive mixing ratio gradient exists above this altitude with the January values at 40 and $45 \mathrm{~km}$ exceeding those in August by factors of 2 or slightly more. In several respects the January result is similar to observations made at middle latitudes. Approximately one half of the profiles previously measured between 37 and 51 degrees North showed an increasing NO mixing ratio between 40 and $45 \mathrm{~km}$. The January Poker Flat result of $8.5 \mathrm{ppbv}$ at $40 \mathrm{~km}$ is consistent with the mean of all mid-latitude data. The distinguishing feature of the high latitude winter profile is the persistence of the steep

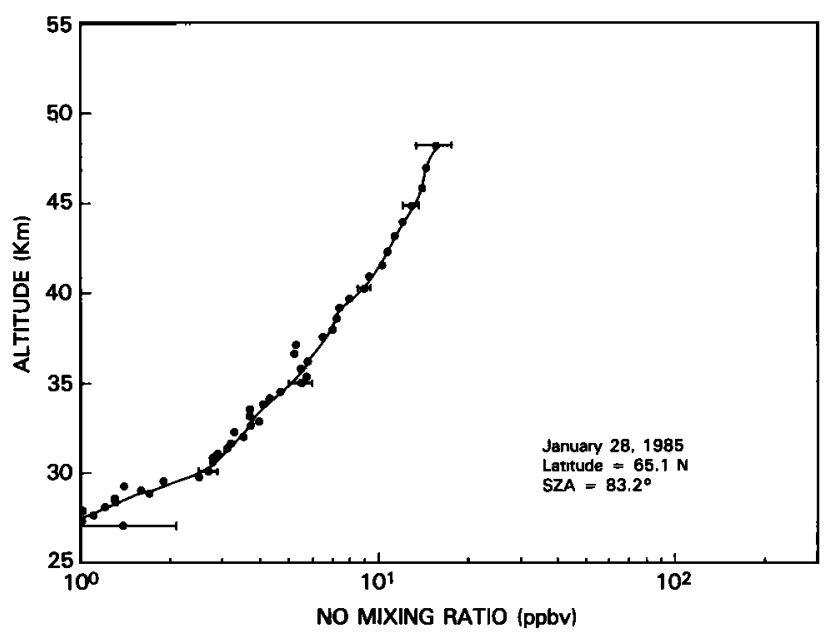

Fig. 2. Nitric oxide mixing ratio profile observed over Poker Flat, Alaska on January 28, 1985. 


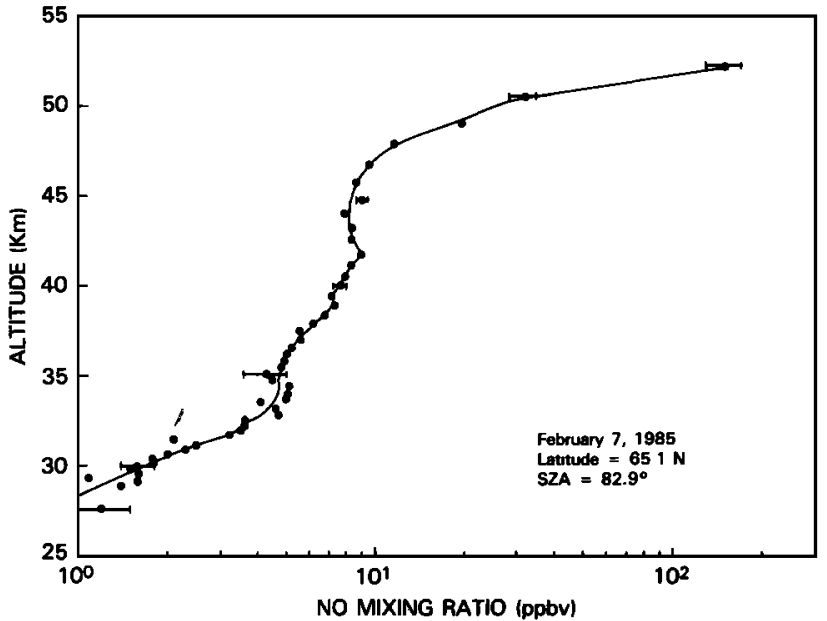

Fig. 3. Nitric oxide mixing ratio profile observed over Poker Flat, Alaska on February 7, 1985.

positive vertical gradient through the uppermost altitude observed. In all mid-latitude profiles obtained previously, the mixing ratio has leveled off or, in most cases, was decreasing at the apex of the measurement.

The profile observed on February 7, 1985, shown in Figure 3, provides convincing evidence that air of thermospheric origin existed near the high latitude stratopause at the time of the measurement. Below $42 \mathrm{~km}$ the February 7 result is similar to that seen on January 28. However, th February profile extends upward to $52.25 \mathrm{~km}$ and reveals an extremely sharp gradient, with a mixing ratio of 148.9 ppov at the peak altitude. This value is typical of that for a mid-latitude NO profile near an altitude of $90 \mathrm{~km}$ (Frederick and Abrams, 1982). Nitric oxide abundances this large cannot be produced in the stratosphere by the ambient chemistry. Although energetic solar particles sporadically create large NO amounts in the mesosphere, we know of no such event near the time of the measurement shown in Figure 3. The polar night LIMS $\mathrm{NO}_{2}$ results of Russell et al. (1984) show longitudinal variations of factors of 4 to 7. Therefore, one should not view the profile of Figure 3 as representative of the zonally averaged state. In support of this statement, the January 28 profile fails to show the extremely steep gradient seen on February 7, at least through the highest altitude observed.

\section{Conclusions}

The differences between upper stratospheric nitric oxide profiles observed from Poker Flat, Alaska in summer and winter reveal the impact of the seasonal ly varying dynamical-chenical environment on the odd nitrogen abundance. The mixing ratios that exist in January and February, with their steep vertical gradients taken with the prevailing atmospheric circulation, are consistent with the idea that nitric oxide produced at greater altitudes reaches the high latitude upper stratosphere or lower mesosphere in winter. Indeed, the extremely large values observed near $52 \mathrm{~km}$ are typical of lower thermospheric No abundances. These results clearly support the existence of a vertical coupling between diverse regions of the atmosphere in the high latitude winter.

Acknowledgements. The authors would like to thank the members at the Poker Flat Research Range who, under the direction of Mr. Niel Brown, did a superior job in supporting this research effort. We would also like to thank Mr. Bruce Scott for doing another great job of coordinating our research program through the auspices of the NASA-Goddard-Wal lops Flight Facility. And finally, thanks go to Mr. Larry Early, director of the Sounding Rocket Branch at the Wallops Flight Facility for assistance without which this research effort would not have been concluded. This research was supported by the National Aeronautics and Space Adininistration under NASA Grant NAG5-230.

\section{References}

Cravens, T.E. and A.I. Stewart, Global morphology of nitric oxide in the lower $E$ region, J. Geophys. Res., 83, 2446-2452, 1978.

Frederick, J.E., and R.B. Abrams, Model studies of nitric oxide fluorescence in the earth's backscattered spectrum, Planet. Space Sci., 30, 137-145, 1982.

Frederick, J.E. and N. Orsini, The distribution and variability of mesospheric odd nitrogen: A theoretical investigation, J. Atmos. Terrest. Phys., 44, 479-488, 1982 .

Frederick, J.E. and G.N. Serafino, Satellite observations of the nitric oxide dayglow: Implications for the behavior of mesospheric and lower themospheric odd nitrogen, J. Geophys. Res., 90, 3821-3830, 1985.

Horvath, J.J., J.E. Frederick, N. Orsini, and A.R. Douglass, Nitric oxide in the upper stratosphere: Measurements and geophysical interpretation, J. Geophys, Res, 88, 1080910817, 1983.

Rusch, D.W., Satellite ul traviolet measurements of nitric oxide fluorescence with a diffusive transport model, J. Geophys. Res., 78, 5676$5686,1973$.

Russe I 1, J.M., III, S. Solomon, L.L. Gordley, E.E. Remsberg, and L.B. Callis, The variability of stratospheric and mesospheric $\mathrm{NO}_{2}$ in the polar winter night observed by LIMS, J. Geophys. Res., 89, 7267-7275, 1984.

Solomon, S., P.J. Crutzen, and R.G. Roble, Photochemical coupling between the thermosphere and lower atmosphere, 1, Odd nitrogen from 50 to $120 \mathrm{~km}$, J. Geophys. Res., 87, 7206-7220, 1982.

Solomon, S., and R.R. Garcia, Transport of thermospheric NO to the upper stratosphere?, Planet Space Sci.., 32, 399-409, 1984.

strobel, D.F., D.M.Hunten, and M.B. McElroy, Production and diffusion of nitric oxide, J. Geophys. Res., 75, 4307-4321, 1970.

J.J. Horvath, Space Physics Research Laboratory, University of Michigan, Ann Arbor, Michigan 48109.

J.E. Frederick, Atmosphric Chemistry and Dynamics Branch, Code 616, NASA/Goddard Space Flight Center, Greenbelt, MD 20771.

(Received May 17, 1985; accepted June 5, 1985.) 